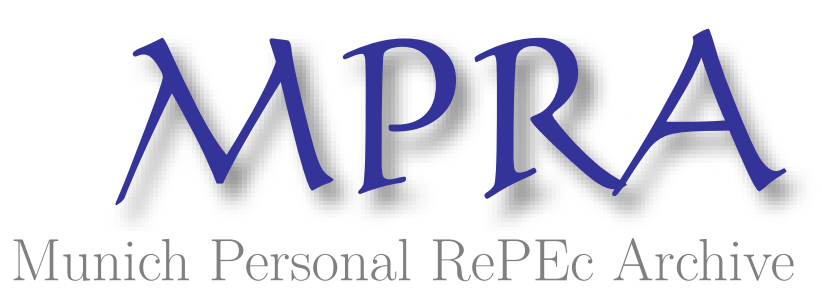

\title{
A Note on Credit Spread Forwards
}

Hertrich, Markus

2015

Online at https://mpra.ub.uni-muenchen.de/67838/

MPRA Paper No. 67838, posted 12 Nov 2015 14:24 UTC 


\title{
A Note on Credit Spread Forwards
}

\author{
Markus Hertrich ${ }^{\mathrm{a}, \mathrm{b}}$ \\ ${ }^{a}$ Department of Finance, University of Basel, Peter Merian-Weg 6, 4052 Basel \\ (Switzerland). Email: markus.hertrich@unibas.ch. \\ ${ }^{b}$ Institute for Finance, University of Applied Sciences Northwestern Switzerland, Peter \\ Merian-Weg 86, 4052 Basel (Switzerland). Email: markus.hertrich@fhnw. ch.
}

\begin{abstract}
This paper presents the most commonly used definition of credit spread forwards, discusses two alternative definitions and proposes one of these definitions as the standardized version that should be used in the future to prevent confusion. In addition, this paper gives an overview about the definition of this credit derivative contract in the most relevant banking and credit risk hand- and textbooks that deal with credit derivatives and exemplifies by means of one textbook that although being a standard textbook for years and read by thousands of practitioners and students, there are still books that erroneously mix these alternative definitions, which motivates the present paper.
\end{abstract}

Keywords: credit derivative, credit spread forward, credit spread swap, hedging, textbook

JEL Classification: A22, A23, A29, A33, G13, G21, G32, M21

\section{Introduction}

Credit spread forwards, also called credit spread swaps, are derivative contracts whose price is related to the difference between the yield of a pre-specified security and the yield of a risk-free reference bond. ${ }^{1}$ Despite being a straightforward derivative contract, the definition of these contracts varies according to which textbook one uses, which makes it necessary to

\footnotetext{
${ }^{1}$ Alternatively, the credit spread forward can be related to the yield difference between two risky bonds.
} 
agree on a standardized definition. Accordingly, this paper first presents in Subsection 2.1 the definition that is more intuitive and then gives an overview about the textbooks that use a definition that accords with this first definition. Second, this paper offers an alternative definition in terms of the market value of the underlying bonds. Third, this paper presents a third definition in Subsection 2.2 and fourth, exemplifies in Section 3 the confusion that a non-standardized definition causes in a textbook that is commonly used in banking and finance. Finally, Section 4 concludes.

\section{Credit Spread Forwards}

\subsection{Definition}

Following the handbook of financial risk managers (Jorion, 2010), the credit spread forward contract is defined as follows:

$$
C F_{T}=\left(C S_{T}-C S_{0}\right) \cdot M D \cdot A
$$

where $C F_{T}$ denotes the nominal payment that is due at the maturity date $T, C S_{T}$ is the actual credit spread at time $T, C S_{0}$ is the agreed-upon credit spread at the time of issue (e.g., the credit spread between A-rated bonds and U.S. Treasury bonds, where the latter is called the "benchmark bond"), $M D$ denotes the modified duration on the corporate bond and $A$ is the notional amount of the forward agreement. Notice that the credit spread $C S_{t}$ at a date $t$ (with $0 \leq t \leq T$ ) represents the default risk (or risk premium) of the underlying risky bond. 
This definition corresponds with the definition of this derivative contract in Anson (1999), Babbel and Fabozzi (1999), Tavakoli (2001), Anson et al. (2004), Bruyere et al. (2006), Douglas (2007), Fabozzi (2007), Maginn et al. (2007), Resti and Sironi (2007) and Petitt et al. (2015), among others. This definition is in line with the general definition of a forward contract, whereby the long position in a forward contract gains when the underlying (here a credit spread) increases and exceeds the "strike price", which in the present case equals $C S_{0}$ :

Figure 1: Payoff Profile of a Credit Spread Forward at the Maturity Date (Long)

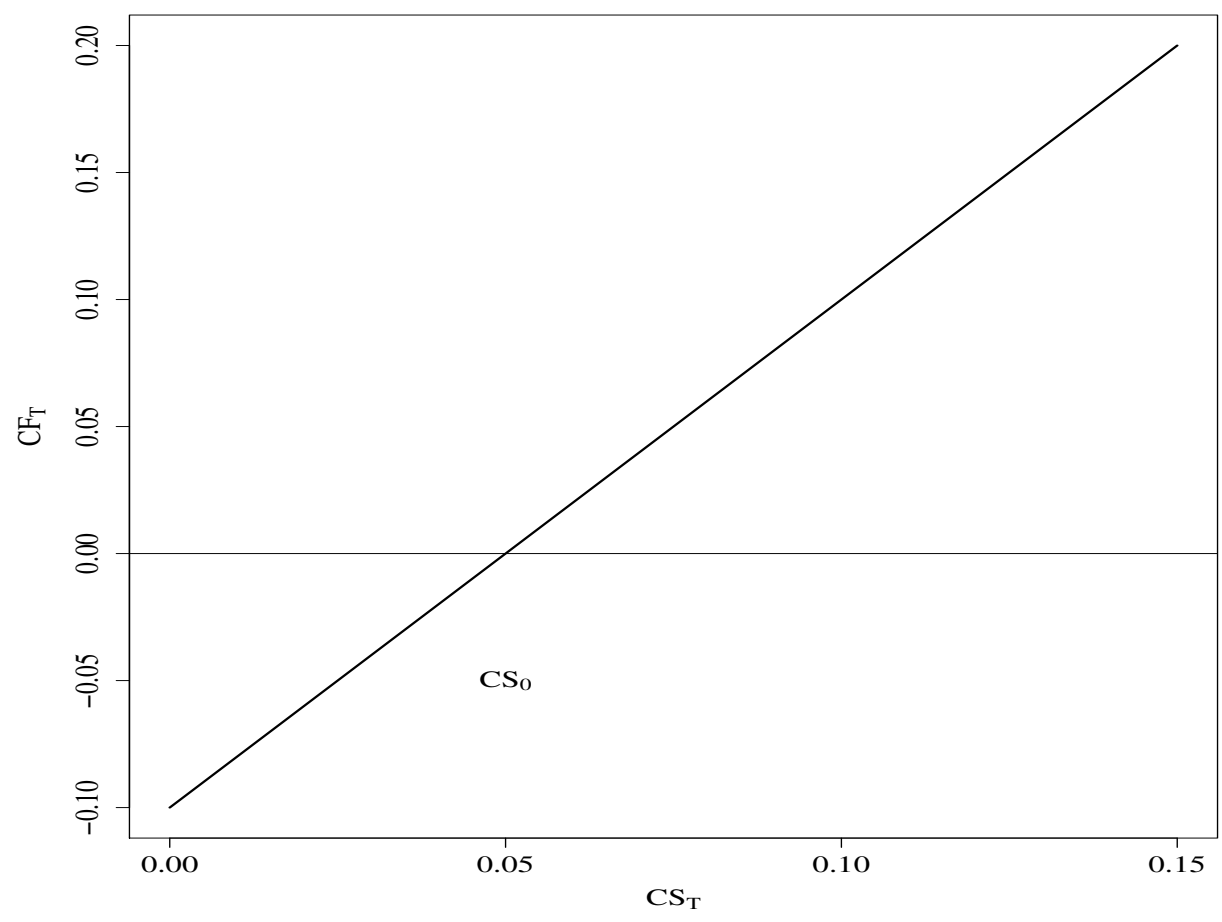

Notes: The figure shows the payoff profile $C F_{T}$ of a credit spread forward at the maturity date $T$, assuming the following parameters: $A=1, C S_{0}=5 \%$ and $M D=2$. 
Similarly, the short position gains when the underlying decreases (i.e., when the credit spread narrows) and falls below $C S_{0}$.

Figure 1 exemplifies how the credit spread $C S_{T}$ between the corporate bond and the benchmark bond will exceed the pre-specified credit spread $C S_{0}$ at the maturity date $T$, if the credit rating of the bond issuer worsens over the time to maturity $T$ (and consequently the credit risk of the underlying risky bond increases). Hence, the credit forward buyer (i.e., the protection buyer) receives a positive payment at time $T$. Accordingly, treasurers, for instance, who want to hedge the credit risk of a risky bond may buy such a credit spread forward and enter a long position.

Similarly, the credit spread forward can be related to the market value of a risky fixed-income security. In this case these credit derivative contracts can be defined as:

$$
C F_{T}=\left[B\left(y+C S_{0}, T\right)-B\left(y+C S_{T}, T\right)\right] \cdot A,
$$

In Equation 2, $B\left(y+C S_{0}, T\right)$ denotes the bond price of a corporate bond at the date of issue with a time to maturity $T$, where the coupon payments are discounted at $y+C S_{0}$, i.e., at the yield to maturity of an equivalent risk-free bond and the credit spread $C S_{0}$. As in Equation 1, whenever the credit spread at maturity $C S_{T}$ exceeds the agreed-upon credit spread $C S_{0}$, the credit spread buyer will receive a positive payment, as in this case the market value of the corporate bond will have decreased over time. 


\subsection{Alternative Definition}

As an alternative to the definition in Section 2.1, the credit forward spread can also be defined as:

$$
\widetilde{C F}_{T}=\left(C S_{0}-C S_{T}\right) \cdot M D \cdot A \text {. }
$$

This definition accords with the definition in Moran (2001), Choudhry et al. (2002), Fabozzi and Choudhry (2004), Meissner (2005), Banks (2006), Banks et al. (2006), Saunders and Cornett (2014). This definition is based on the idea that whenever the market value of a corporate bond increases (decreases) compared to the price of an equivalent risk-free bond and accordingly the credit quality of the bond issuer improves (worsens), whereby the credit spread $C S_{T}$ narrows (widens), the credit forward buyer gains (looses).

Although both definitions (i.e., Equations 1 and 3) are equally valid, this paper favors the first definition in the case where the credit spread forward is explicitly related to the difference between the yield of a pre-specified bond and the yield of a risk-free reference bond, since in this case the long position corresponds to the situation where the derivative contract buyer gains whenever the underlying increases.

\section{A Cautionary Note}

It is important not to mix both definitions. For instance in the standard textbook in banking developed by Saunders and Cornett (2014), the section 
that deals about managing credit risk with credit spread forwards defines these derivative contracts as in Equation 3, whereby the credit spread seller gains, whenever the credit quality of the bond issuer worsens. However, when discussing the questions and problems that complement the textbook, the credit spread buyer gains, whenever the credit quality of the bond issuer worsens, which accords with the definition in Equation 1:

Question 1: "What is the gain on the purchase of a USD 20 million credit forward contract with a MD of 7 years if the credit spread between a benchmark Treasury bond and a borrowing firm's debt decreases by 50 basis points" (Saunders and Cornett, 2014)?

Answer 1: The answer specifies that credit forward buyer gains in this case $\left(C S_{T}-C S_{0}\right) \cdot M D \cdot A$.

Question 2: "How is selling a credit forward similar to buying a put option?" (Saunders and Cornett, 2014)?

Answer 2: The answer specifies that a credit forward seller gains if the credit quality of the bond issuer improves such that the credit spread at the maturity date falls below the same metric at the date of issue and then compares it to the payoff when buying a put option, where the long position gains, whenever the underlying price decreases.

\section{Conclusion}

This paper presents the most commonly used definition of credit spread forward contracts and two alternative definitions, and explains why this paper favors one of the definitions. Specifically, this paper explains why it 
favors one of the presented definitions, suggesting that in the future financial economists should agree on one definition to prevent confusion. More importantly, this paper lists the most commonly hand- and textbooks that include these credit derivatives and presents an example from a standard textbook in banking, where the authors unfortunately mix both definitions when discussing some questions and problems. 


\section{References}

Anson, M. J. P., 1999. Credit Derivatives. Hoboken (New Jersey): John Wiley \& Sons.

Anson, M. J. P., Fabozzi, F. J., Choudhry, M., Chen, R.-R., 2004. Credit Derivatives: Instruments, Applications, and Pricing. Hoboken (New Jersey): John Wiley \& Sons.

Babbel, D. F., Fabozzi, F. J., 1999. Investment Management for Insurers. New Hope (Pennsylvania): Frank J. Fabozzi Associates.

Banks, E., 2006. Synthetic and Structured Assets. Hoboken (New Jersey): John Wiley \& Sons.

Banks, E., Glantz, M., Siegel, P., 2006. Credit Derivatives: Techniques to Manage Credit Risk for Financial Professionals. McGraw-Hill Financial Education Series.

Bruyere, R., Cont, R., Copinot, R., Fery, L., Jaeck, C., Spitz, T., 2006. Credit Derivatives and Structured Credit: A Guide for Investors. Hoboken (New Jersey): John Wiley \& Sons.

Choudhry, M., Joannas, D., Pereira, R., Pienaar, R., 2002. Capital Market Instruments: Analysis and Valuation. London: Financial Times Prentice Hall.

Douglas, R. (Ed.), 2007. Credit Derivative Strategies. Bloomberg.

Fabozzi, F. J., 2007. Fixed Income Analysis. Hoboken (New Jersey): John Wiley \& Sons.

Fabozzi, F. J., Choudhry, M., 2004. The Handbook of European Fixed Income Securities. Hoboken (New Jersey): John Wiley \& Sons.

Jorion, P., 2010. Financial Risk Manager Handbook. Hoboken (New Jersey): John Wiley $\&$ Sons.

Maginn, J. L., Tuttle, D. L., McLeavey, D. W., Pinto, J. E., 2007. Managing Investment Portfolios: A Dynamic Process. Hoboken (New Jersey): John Wiley \& Sons.

Meissner, G., 2005. Credit Derivatives: Applications, Pricing, and Risk Management. Oxford: Blackwell Publishing.

Moran, T. H. (Ed.), 2001. International Political Risk Management. The International Bank for Reconstruction and Development.

Petitt, B. S., Pinto, J. E., Pirie, W. L., 2015. Fixed Income Analysis. Hoboken (New Jersey): John Wiley \& Sons.

Resti, A., Sironi, A., 2007. Risk Management and Shareholders' Value in Banking. Hoboken (New Jersey): John Wiley \& Sons.

Saunders, A., Cornett, M. M., 2014. Financial Institutions Management. McGraw-Hill Education.

Tavakoli, J. M., 2001. Credit Derivatives \& Synthetic Structures: A Guide to Instruments and Applications. Hoboken (New Jersey): John Wiley \& Sons. 